\title{
A new species of Drymaeus endemic from Currais Archipelago, Paraná, Brazil (Pulmonata, Bulimulidae)
}

\author{
Luiz Ricardo L. Simone'; Carlos Eduardo Belz ${ }^{2,3}$ \& Marcos de Vasconcellos Gernet ${ }^{2,4}$ \\ ${ }^{1}$ Universidade de São Paulo (USP), Museu de Zoologia (MZUSP). ORCID: http://orcid.org/0000-0002-1397-9823. E-mail: Irsimone@usp.br \\ 2 Universidade Federal do Paraná (UFPR), Setor de Ciências da Terra (CT), Centro de Estudos do Mar (CEM), \\ Laboratório de Ecologia Aplicada e Bioinvasões (LEBI0). Pontal do Paraná, PR, Brasil. \\ ${ }^{3}$ ORCID: http://orcid.org/0000-0002-2381-8185. E-mail: belzoceanos@gmail.com \\ ${ }^{4}$ ORCID: http://orcid.org/0000-0001-5116-5719. E-mail: Imv.gernet@gmail.com
}

\begin{abstract}
The new bulimulid species, Drymaeus currais sp. nov., is described based on shell and anatomical features. It is endemic of Guapirá Island, belonging to the Currais Archipelago, a small protected area off Paraná coast. The species is thus, based at least on endemicity, endangered. It has as closest species D. castilhensis, another endemic species of Castilho Island, $\sim 70 \mathrm{~km}$ northwards. Its main exclusivities are a banded shell (except for periumbilical area); a ureter $\sim 1 / 3$ opened (furrow); an external anus; a slightly different buccal and intestinal arrangement; a penis lacking internal chambers; a small receptacle with a genital appendix. Zoobank Register: urn:Isid:zoobank.org:pub:25B25A8B-CED0-4284-A799-5383998BE481.
\end{abstract}

Key-Words. New species; Endemic; Endangered; Anatomy; Morphology; Taxonomy.

\section{INTRODUCTION}

The taxonomy of land snails from southwestern Atlantic islands has been investigated in a long-term project. Both remote oceanic island (about a thousand km off) as well as islands located closer to the Brazilian coast (about 20-30 km off) have shown a high degree of endemicity of the land snail species, something close to $100 \%$. The latest paper of this project described three new bulimulids, each one endemic from an island off the São Paulo coast - Castilho, Queimada Pequena and Alcatrazes (Simone \& Amaral, 2018).

Paraná is the neighboring state south from São Paulo, and also has some oceanic islands. One of them is the Currais Archipelago (Fig. 1). The Archipelago is located in the central portion of the Paraná coast $\left(25^{\circ} 44^{\prime} 07.74^{\prime \prime} \mathrm{S}, 48^{\circ} 21^{\prime} 58.12^{\prime \prime} \mathrm{W}\right)$ approximately six nautical miles from the municipality of Pontal do Paraná, and consists of a group of three small rocky islets. Grapirá Island represents $81 \%$ of the total area of the archipelago, estimated in $73,534 \mathrm{~m}^{2}$. From the rest of the area, 19\% includes two small rocks: the first, with $7,748 \mathrm{~m}^{2}$, and the second, on the west side of the archipelago, with $6,249 \mathrm{~m}^{2}$ (Borzone et al., 1999). The archipelago belongs to the National Marine Park of the Currais Islands, a marine protected area of 1,357.7 hectares (ICMBio, 2020).
The Currais Islands come from a Precambrian crystalline rocky outcrop of the so-called Coastal Granitoid Belt, presenting a lithology formed by intrusive and migmatite granites. The submerged portion adjacent to these is characterized by sandy marine sedimentation with predominantly sand granulation thin or medium (0.125-0.5 mm) and inclination less than $2^{\circ}$ (Bigarella et al., 1965).

The climate of the coastal plain of Paraná, where the Currais archipelago is located, is Cfa type (Humid Subtropical Climate - Mesothermal), with an average of the warmest month above $22^{\circ} \mathrm{C}$ and in the coldest month below $18^{\circ} \mathrm{C}$, with no defined dry season, hot summer and less frequent frosts (Vanhoni \& Mendonça, 2008).

The vegetation formation of the archipelago is of the Dense Ombrophilous Forest of Low Lands type, with pioneer rupicolous formations of marine influence along the rocky shores. This phytogeographic unit is characterized by indisputable environmental importance, with high biological diversity and a large number of endemism. It presents a very typical floristic and structural composition composed of different communities along the altitude gradient and the pioneer formations, ranging from herbaceous vegetation to tree remainings rich in epiphytes (Roderjan et al., 2002).

Its main island, Guapirá, is a little larger than a football field; it is the tip of a small mountain cov- 
ered by a luxuriant Atlantic Rainforest fragment. In that island, a population of a pretty land snail occurs, initially identified as Drymaeus castilhensis Simone \& Amaral, 2018 , by its similar shell features, a species so far endemic of the Castilho Island, separated by $\sim 70 \mathrm{~km}$ of ocean northwards from Currais. However, the complementary anatomical study revealed important anatomical differences, allowing the specific separation. The new entity is formally described herein.

The description of the new species endemic from a relatively small island reinforces the necessity of environmental protection of the Currais Archipelago, another important issue that merits proper emphasis.

The genus Drymaeus has about 300 species, 49 of them in Brazil (Simone, 2006; Birckolz et al., 2016). It is widespread from south of North America, Caribbean islands, Central America, up to central Argentina along almost the entire South America, including the Andes and all mainland forests. Its distinction with other bulimulid genera, such as Naesiotus Albers, 1850, Mesembrinus Albers, 1850, Leiostracus Albers, 1850, is not straightforward, and some degree of overlapping exists. Normally, Drymaeus have bulimuliform shells with rich color and delicately reticulated protoconch.

\section{MATERIAL AND METHODS}

The specimens were collected in duly authorized projects (SISBIO license number 47215-3), as the region is protected; a complete list of examined material follows the species description. The samples were fixed unrelaxed in $75 \% \mathrm{EtOH}$. The dissections were performed by standard techniques, with the specimens immersed in alcohol, examined in dissecting stereomicroscopes. All drawings were done with the aid of a camera lucida, and most drawing normally are based on several specimens. Photos of all dissecting steps were made by digital camera coupled to the microscope. SEM examinations were performed in a Zeiss device of the Laboratory of Electronic Microscopy of the Museu de Zoologia da Universidade de São Paulo - MZSP. This institution also houses most of type material.

Anatomical abbreviations: aa, anterior aorta; ac, albumen chamber; ad, albumen gland duct; ag, albumen gland; an, anus; au, auricle; bc, bursa copulatrix; bd, bursa copulatrix duct; bg, buccal ganglion; bm, buccal mass; ce, cerebral ganglion; cv, pulmonary (efferent) vein; da, digestive gland anterior lobe; $\mathbf{d d}$, duct to digestive gland; df, dorsal folds of buccal mass; dg, digestive gland posterior lobe; eh, epiphallus; eo, spermoviduct; es, esophagus; fo, free oviduct; fp, genital pore; ga, genital appendix; go, gonad; hd, hermaphrodite duct; in, intestine; jw, jaw; ki, kidney; m1-m10, extrinsic and intrinsic odontophore muscles; $\mathbf{m b}$, mantle border; $\mathbf{m f}$, mantle fold; mj, jaw and peribuccal muscles; mo, mouth; ne, nephrostome; $\mathbf{n r}$, nerve ring; od, odontophore; pc, pericardium; pe, penis; pm, penis muscle; pn, pneumostome; pp, pedal-pleural ganglia; ps, penis sheath; pt, prostate; pu, pulmonary cavity; ra, radula; rt, rectum; sa, salivary gland aperture; sd, salivary gland duct; se, septum between odontophore and esophageal origin in buccal mass; sg, salivary gland; sm, spermatophores inside duct of bursa; sp, spermoviduct inner longitudinal fold; sr, seminal receptacle; st, stomach; tg, integument; to, tissue on radular ribbon preceding radular exposed region in buccal cavity; ua, ureter aperture; un, union of mantle border with nuchal surface; up, primary ureter; ur, secondary ureter; ut, uterus; vd, vas deferens; ve, ventricle; vg, vagina; vm, visceral mass; vp, pulmonary vessels.

Institutional abbreviations: LEBIO, Laboratório de Ecologia Aplicada e Bioinvasões do Centro de Estudos do Mar da Universidade Federal do Paraná; MZSP, Museu de Zoologia da Universidade de São Paulo.

\section{RESULTS}

\section{Systematics}

\section{Drymaeus currais new species}

(Figs. 1-36)

urn:Isid:zoobank.org:act:D17AD2E5-D03C-447A-95E0-DFAB83F34F12

Types: Holotype: MZSP 150548 (Figs. 2-4). Paratypes: MZSP 135683 (19 dissected specimens), LEBIO 577, 5 specimens, all from type locality.

Type locality: Brazil. Paraná; off Pontal do Paraná, Currais Archipelago, Guapirá Island, 2544'09.32"S, $48^{\circ} 21^{\prime} 55.34^{\prime \prime} \mathrm{W}$ (Belz, Gernet \& Colley col., 2015).

Additional non-type material examined from type locality: MZSP 29634, 2 dissected specimens (01.xii.1988); MZSP 135684, 3 specimens, MZSP 135685, 13 specimens, MZSP 136031, 2 specimens, MZSP 136032, 5 specimens, MZSP 143544, 3 specimens (26.iii.2015).

Etymology: The epithet is in apposition, as a reference to the location of occurrence, derived from Currais Archipelago.

Diagnosis: shell conical, aperture ample, weakly deflected. Color white-cream, mostly with strong axial, dark brown spots; peri-umbilical area lacking spots; some rare specimens uniformly yellowish beige. Secondary ureter closed only in posterior 2/3, furrow-like in third preceding pneumostome. Pulmonary vases particularly dense, mainly on third preceding pneumostome. Anus external to pneumostome, opened directly outside. Aperture of salivary glands lateral in middle level of buccal cavity. Intrinsic pair of odontophore muscles $\mathrm{m} 7$ originating in cartilages close to m6; presence of odontophore pairs $\mathrm{m} 1 \mathrm{a}$ and $\mathrm{m} 3$. Sigmoid intestinal loop relatively short. Penis slender and long, lacking clear inner chambers. Inner spermoduct of spermoviduct protected by tall fold. Seminal receptacle small, with additional elongated diverticulum called genital appendix. Albumen gland duct single, elongated. Pleural ganglia inconspicuous. 


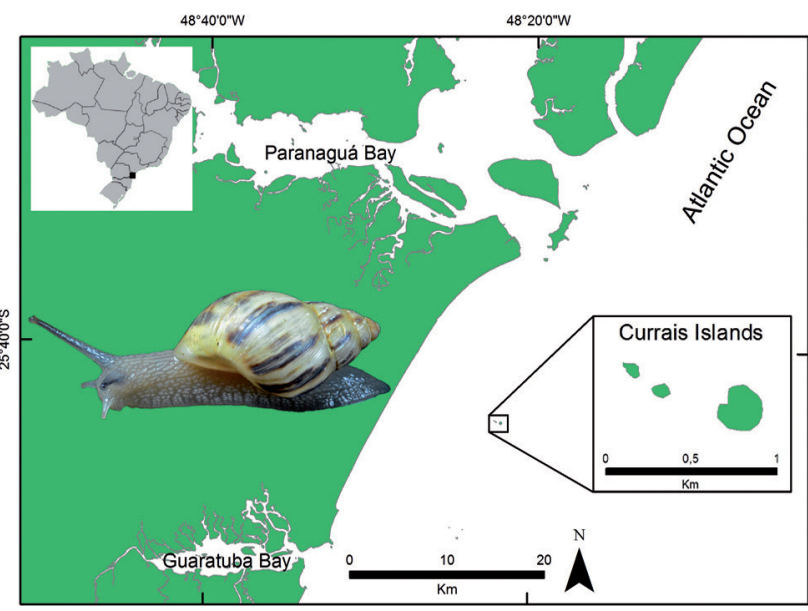

Figure 1. Map of Paraná coastal area, showing the Currais archipelago location and its profile in highlight. Occurrence of specimens in the larger island (east one). A living crawling specimen also shown (shell length $\sim 20 \mathrm{~mm}$ ).

\section{Description}

Shell: (Figs. 1-9) adult shell around $35 \mathrm{~mm}$, conical-oval; apex bluntly acuminated; greatest width on last whorl; width $\sim 1 / 2$ shell length. Basal color white to pale-cream; pattern of dark-brown spots arranged in irregular axial bands, slightly more concentrated in middle region of whorls; peri-umbilical area flanked by area lacking spots (Figs. 2-6); dark spots absent in $\sim 10 \%$ of specimens, being purely yellowish-cream (Figs. 7-8). Spire angle $\sim 55^{\circ}$. Protoconch of 2 whorls, $\sim 6 \%$ of total shell length, uniformly sculptured by delicate reticulate pattern (Fig. 9), with $\sim 25$ spiral lines in last whorl; transition to teleoconch clear, slightly prosocline (Fig. 9: arrow). Teleoconch smooth, except for growth lines, of $\sim 4$ whorls. Whorls profile slightly convex. Suture well-marked, slightly oblique (diagonal) to columellar axis. Aperture prosocline ( $20^{\circ}$ from longitudinal general axis) (Fig. 3), oval; $\sim 50 \%$ of shell length, $\sim 60 \%$ of shell width. Peristome slightly reflected, especially on columellar region, partially covering umbilicus (Figs. 2, 5, 7). Body whorl 1/2 shell length. Umbilicus narrow.

Head-foot: of usual shape. Color uniformly clear. Columellar muscle thick, 1.8 whorls in length.

Mantle organs: (Figs. 23-26) mantle border thick, lacking pigments. Pneumostome (pn) protected by ventral, right simple flap (mf), with $\sim 1 / 5$ of aperture length. Dorsal fold about double of ventral flap, 1.5-times longer. Pneumostome (pn) 1/9 of aperture length, bearing air entrance, urinary escape (Fig. 24: ua) in left-anterior side (Fig. 23: pn), and anus in right-posterior side, separated by transverse fold (Fig. 23: an). Lung of 1.5 whorls in length, tice longer than wide. Pulmonary vessels conspicuous all along right side (Fig. 24), mostly bearing transverse, rather perpendicular vessels, clustered, sometimes bifurcating or anastomosing; in left side of pulmonary vein (cv), visible vessels only in anterior third, occupying right $\sim$ half of this area, constituted by transverse vessels of similar fashion as right side, but inserting in longitudinal vessel (Fig. 24: vp), in such anterior end converge with anterior end of pulmonary vessel as part of collar vessel (Fig. 26: co). Remaining regions of lung almost smooth, with imbricated vessels of difficult visualization. Pulmonary vein (cv) running longitudinally between middle and right thirds of pallial cavity roof, somewhat equidistant from rectum all along its length. Reno-pericardial area triangular, located posteriorly at middle level of posterior end, occupying 25\% of cavity length and $\sim 70 \%$ of its width (details below). Rectum (rt) and ureter (ur) narrow, running along right edge. Urinary aperture very elongated (Figs. 24, 13: ua), occupying $\sim 1 / 3$ of ureter length; its posterior end slightly rounded, its anterior end just left from anus, T-shaped, being its left branch longer and anteriorly protected by special fold (Fig. 26: pn).

Visceral mass: (Fig. 25) 3.5 whorls in length. Both digestive gland lobes pale greenish beige in color. Anterior lobe (da) flattened, occupying 1/4 of visceral volume, located just posteriorly to pallial cavity, continuous to kidney. Posterior lobe (dg) with 2.5 spiral whorls, with 45\% of visceral volume. Stomach with $\sim 1 / 8$ of visceral volume, located between both digestive gland lobes, about one whorl posterior to pallial cavity (st). Digestive tubes (described below) surrounding anterior lobe of digestive gland. Gonad clearly multi-lobed, greenish-cream color, encased between posterior lobe of digestive gland and columella, occupying $\sim 1 / 10$ of visceral volume.

Circulatory and excretory systems: (Figs. 13, 24, 25) Pericardium (pc) 3-times as long as wide, located longitudinally between middle and left thirds of posterior end of pallial roof; occupying $~ 5 \%$ of lung area. Auricle (au) located anteriorly, as continuation from pulmonary vein (cv), slightly larger than ventricle (ve). Kidney (ki) simple, mostly solid, dorso-ventrally flattened; size reported above; somewhat triangular, width $\sim 2 / 3$ of length; inner lobe constituted by longitudinal, tall folds converging anteriorly to middle axis of structure (Fig. 13). Nephropore small, longitudinal slit in anterior-left corner, turned right (Figs. 24, 25: ne). Primary and secondary ureter complete and closed (tubular); primary ureter (up) lying on right edge of kidney towards posterior and right, after forming strong curve, running afterwards anteriorly, as secondary ureter (ur) along entire left edge of rectum, except for longitudinal urinary aperture of $\sim 1 / 3$ of its length (ua) (details above).

Digestive system: (Figs. 25, 27, 28) Arrangement of foregut essentially same as that described for Drymaeus castilhensis (Simone \& Amaral, 2018: 171-172, figs. 41-44) except for: $\mathbf{m} \mathbf{1} \mathbf{v}$, ventral pair of jugal muscle inserted in middle region of ventral haemocoel surface just posterior to buccal mass, running anteriorly, insertion in mouth close to median line; $\mathbf{m} \mathbf{1 a}$, small pair of lateral jugal muscles, originated in lateral surface of haemocoel, running short distance, inserting in latero-posterior region of buccal mass; $\mathbf{m} \mathbf{2}$, pair of retractor muscles of buccal mass slightly narrower and 1.5-times longer; $\mathbf{m 3}$, pair of super- 
ficial muscles running transversally along postero-lateral surface of buccal mass, from dorso-lateral region to region close to radular nucleus at $\mathrm{m} 2$ insertion; $\mathbf{m 1 0}$, pair of ventral protractor muscles of buccal mass slightly thinner and narrower; circular muscles of oral tube (mc) not so developed. Radular sac short, not extending beyond odontophore. Jaw plate (Fig. 10: jw) with medial slightly constriction, $\sim 12$ pairs of transverse folds medially narrow, gradually becoming wider towards lateral. Radular nucleus inlaid inside odontophore.
Radula (Figs. 14-22) as long as odontophore; with rachidian teeth, and $\sim 55$ pairs of lateral teeth; no clear distinction between lateral and marginal teeth (Figs. 18, 19, 21, 22); all teeth with relative long and flattened base, located closely from neighboring rows; central set of cusps rather small, located in anterior end of base. Rachidian tooth (Figs. 15, 16, 20: arrow) small, relatively reduced, $\sim$ half of neighboring teeth, $\sim 1 / 70$ of radular width; base $\sim 3$-times longer than wide, flattened, barely rectangular; central cusp with $\sim 1 / 2$ of base's size, tip blunt; pair

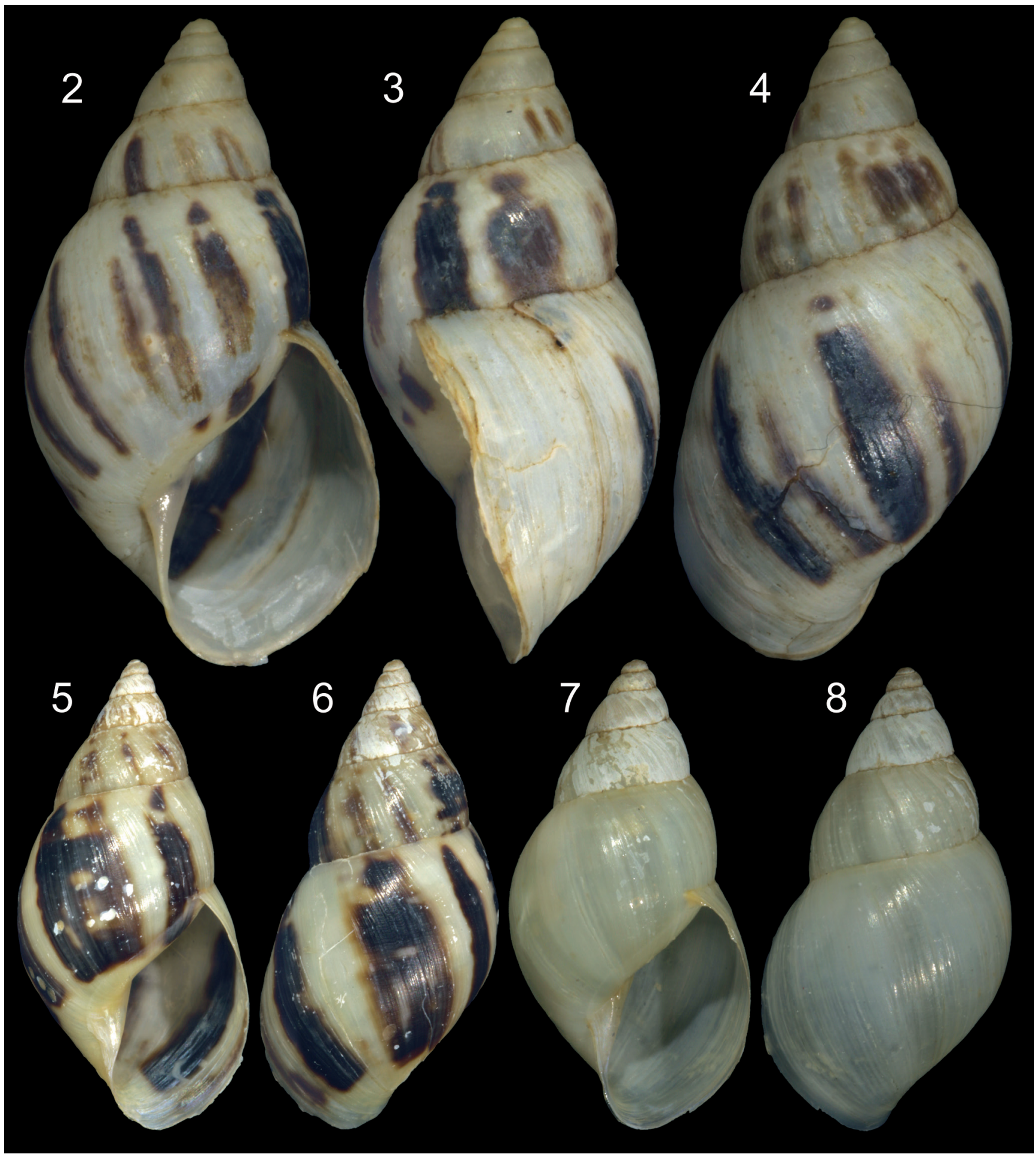

Figures 2-8. Drymaeus currais sp. nov. shell of types; (2-4) Holotype MZSP 150548 (L 29.6), frontal, right and dorsal view. (5-8) Paratypes MZSP 135683. (5-6) Frontal and dorsal view ( $\mathrm{L} 30.7 \mathrm{~mm})$. 
of basal cusps with $\sim 1 / 5$ of central cusp's size (Fig. 16). Lateral teeth similar to rachidian, except in being $\sim$ twice larger, asymmetrical, arched towards lateral region, cutting edge $\sim 1.5$-times larger than that of rachidian; lateral teeth gradually weakly decreasing towards lateral; set of cusps with $\sim 1 / 2$ of length of base; central cusp bluntly pointed; basal cusps strongly asymmetrical, outer basal cusp almost as large as central cusp in more central teeth, almost originating from base (Fig. 16), gradually becoming smaller and sometimes separated from central cusp (Fig. 15); inner cusp 3-4-times smaller than lateral cusp. Marginal teeth starting with no clear boundary with lateral teeth; shaped similarly to lateral teeth, except for being weakly smaller and with set of cusps broader and slightly less pointed (Figs. 17-19, 21-22); inner basal cusp gradually becoming as large as outer basal cusp and bifid, dividing in two cusps (Figs. 17, 21, 22); teeth becoming very narrow in margins (Fig. 19). Each radular row slightly arched disposed from both sides from rachidian (Fig. 14).

Salivary glands covering esophagus in its region preceding its anterior 1/6 (Fig. 25: sg), forming two elongated, white, thin masses. Each salivary duct differentiable in anterior side of glands, relatively broad, with $\sim 1 / 10$ esophageal width (Figs. 25, 27, 28: sd). Salivary duct run- ning in both sides of esophageal origin (Figs. 27, 28: sd), penetrating buccal mass wall in region close to buccal ganglia (Fig. 27: sd), running immersed in buccal dorsal wall along $\sim 1 / 4$ its length (Fig. 28: sd). Salivary ducts opening wide, in middle level of dorsal folds, on their middle side (Fig. 28: sa).

Esophagus 1 whorl long, with thin, flaccid walls lacking clear subdivisions (Fig. 25: es). Stomach (Fig. 25: st) relatively narrow, curved, not bulged; position and size described above (visceral mass); gastric walls thin, flaccid; inner surface smooth. Esophageal insertion on posterior side, intestinal origin on anterior side, both close to columella. Duct to anterior lobe of digestive gland located at some distance from stomach, highly branched, covering adjacent intestinal origin and loop (Fig. 25: dd-right). Duct to posterior lobe of digestive gland located short distance from esophageal insertion (Fig. 25: dd-left). Intestine half of width of esophageal insertion, all along its length, including narrow sigmoid loop in anterior lobe of digestive gland (Fig. 25: in). Rectum and anus position described above (pallial cavity) (Fig. 24: rt, an). Anus sessile, as slit in right end of mantle edge directly turned outside, but still inside pneumostome (Fig. 23); inner surface with 8-10 longitudinal, simple folds (Fig. 26: an).

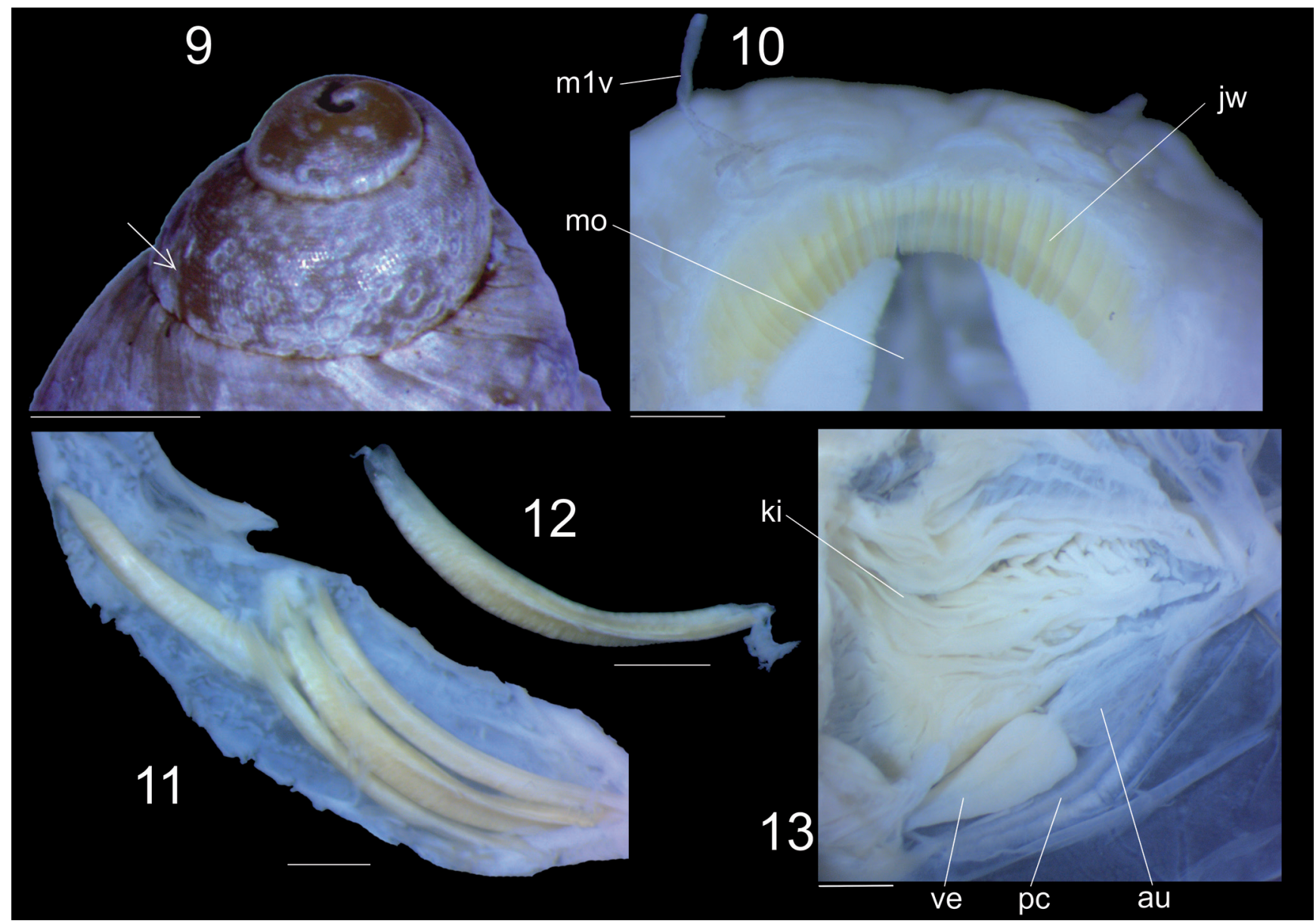

Figures 9-13. Drymaeus currais sp. nov. shell and anatomical details. (9) Protoconch of paratype MZSP 135683\#3 (young specimen of $14.2 \mathrm{~mm}$ ), arrow showing transition with teleoconch. Scale $=1 \mathrm{~mm}$. (10) Anterior region of mouth, ventral view, integument removed. Scale $=0.5 \mathrm{~mm}$. (11) Duct of bursa sectioned longitudinally, showing 4 spermatophores inside. Scale $=1 \mathrm{~mm}$. (12) Isolated spermatophore. Scale $=1 \mathrm{~mm}$. (13) Reno-pericardial area, ventral view, ventral wall of kidney opened along its left edge and deflected right (upwards) to show inner tissue, ventral pericardial wall deflected left (downwards). Scale $=1 \mathrm{~mm}$. 


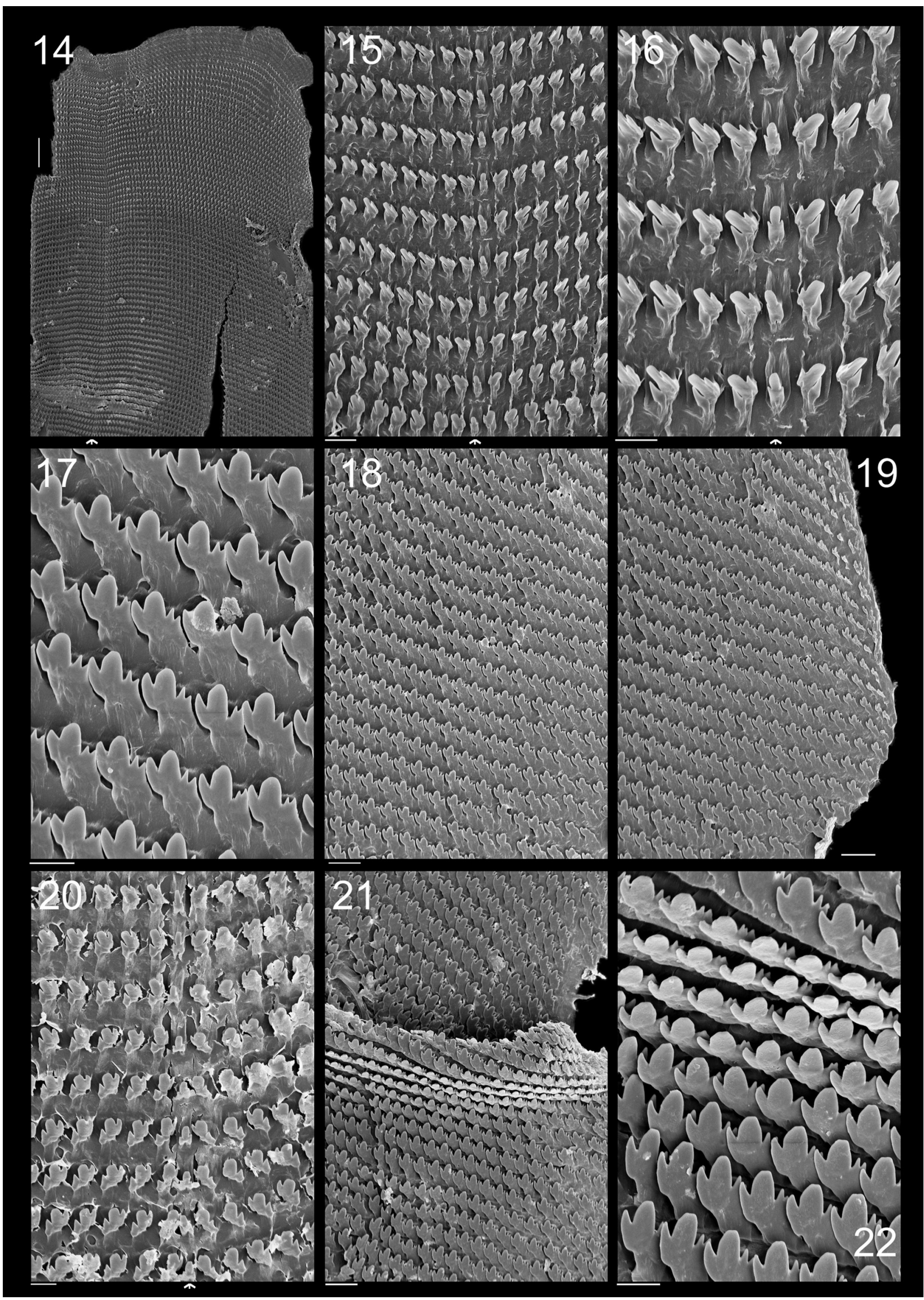

Figures 14-22. Drymaeus currais sp. nov. radulae in SEM; (14) Holotype, wide view. Scale $=200 \mu \mathrm{m}$. (15) Same, higher magnification. Scale $=30 \mu \mathrm{m}$. (16) Same, higher magnification. Scale $=20 \mu \mathrm{m}$. (17) Detail of lateral region. Scale $=20 \mu \mathrm{m}$. (18) Same, lower magnification. Scale $=50 \mu \mathrm{m}$. (19) Detail of marginal region. Scale $=50 \mu \mathrm{m}$. (20) Paratype MZSP 135683, detail of central region. Scale $=20 \mu \mathrm{m}$. (21) Detail of lateral-marginal region, middle region folded. Scale $=50 \mu \mathrm{m}$. (22) Same, higher magnification. Scale $=20 \mu \mathrm{m}$. Arrows showing rachidian column. 
Genital system: (Figs. 29-34) gonad position described above (visceral mass), composed of 4-5 lobes with minute digitiform acini (Fig. 29: go). Hermaphroditic duct (Figs. 29, 19: hd) narrow and weakly coiled in both ends, gradually becoming very wider (up to 5-times wider) and more intensely coiled in middle third (Fig. 29: hd); inserting in left side of receptacle's base (Fig. 32: hd). Seminal receptacle (Figs. 29, 32: sr) relatively small, sac-like, $\sim$ twice longer than wide, with twice hermaphroditic duct width. Fertilization complex simple, located at narrow and elongated base of seminal receptacle (Fig. 32) as duct of seminal receptacle; as long as length of receptacle. Presence of genital appendix (Figs. 29, 32: ga), as wide as terminal width of hermaphrodite duct, inserted just posterior to it in seminal receptacle's base; weakly coiled, 3-times longer than receptacle. Fertilization complex totally immersed in albumen gland (Fig. 32), inserting in posterior end of spermoviduct, in base of albumen gland duct (Fig. 32: ad) relatively wide, simple, $\sim 3$-times wider than receptacle's duct. Albumen gland (Figs. 29, 32: ag) solid, white, elliptical, 1.5 -times larger than gonad $(\sim 1 / 3$ whorl). Albumen gland duct subterminal, connected to distal end of spermoviduct (Fig. 32: ad), in lateral, large albumen chamber (Fig. 32: ac); widely connected to distal end of spermoviduct. Spermoviduct (eo) of $\sim 1.5$ whorl in length, slightly narrower than albumen gland,

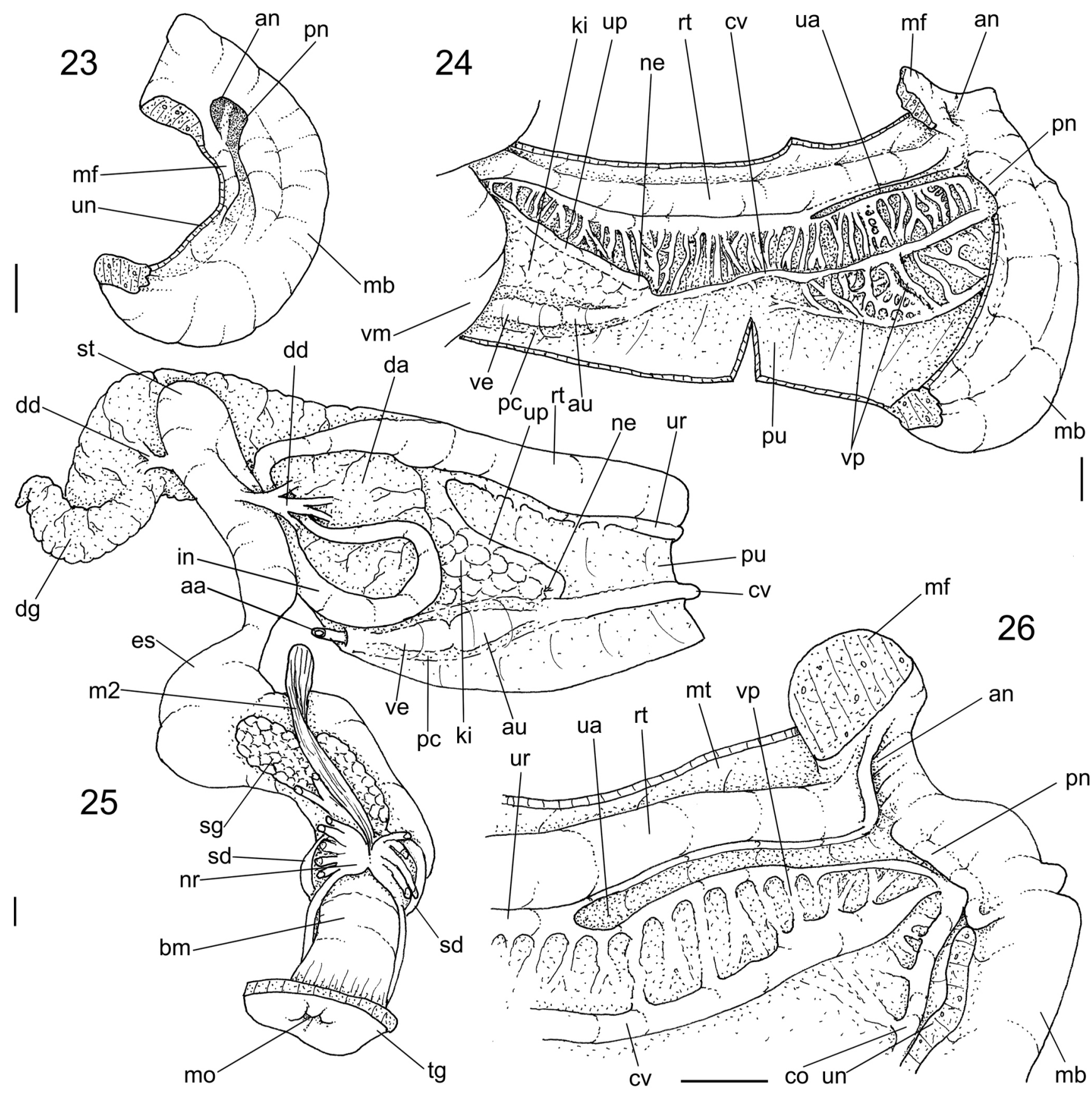

Figures 23-26. Drymaeus currais sp. nov. anatomy; (23) Mantle border as in situ, frontal view. (24) Pallial (pulmonary) cavity, ventral inner view, inner mantle fold deflected upwards. (25) Digestive tubes and some adjacent structures, mainly from visceral mass and posterior region of pulmonary cavity, buccal mass in dorsal view, remaining ventral view, nephrostome (ne) seen by translucency. (26) Anterior-right region of pulmonary cavity, ventral-inner view, inner mantle fold (mf) sectioned and deflected upwards. Scales $=2 \mathrm{~mm}$. 
ca. 20-times longer than wide; intensely coiled and difficulty to rectify. Prostate gland occupying $\sim 1 / 4$ of spermoviduct surface and $\sim 1 / 5$ its volume (Fig. 33: pt). Uterus occupying $\sim 3 / 4$ of spermoviduct space, external walls thick-glandular (Figs. 29, 31, 32: ut), inner surface completely covered by ample transverse folds. Sperm grove simple in posterior 2/3 of spermoviduct (Fig. 33: sp), protected ventrally by tall fold; abruptly becoming tubular becoming, as vas deferens in anterior end of spermoviduct (Fig. 31: vd). Free oviduct short, $\sim 1 / 20$ of sper- moviduct length, Vagina $\sim 1 / 10$ spermoviduct length (Figs. 29, 31: vg); inner surface simple, with 4-5 longitudinal, low, wide folds (Fig. 31: vg). Bursa copulatrix $\sim 2 / 3$ of spermoviduct length; bursa duct as wide as adjacent spermoviduct in its origin (Fig. 31), gradually narrowing towards posterior end (Fig. 29: bd); bursa oval, 1/5 of albumen gland size (Fig. 29: bc), located encased between pericardium and adjacent intestinal loop. Some specimens with 4-5 elongated, simple spermatophores in bursa duct's base (Figs. 11, 12, 29: sm). Penis 1/2 of sper-

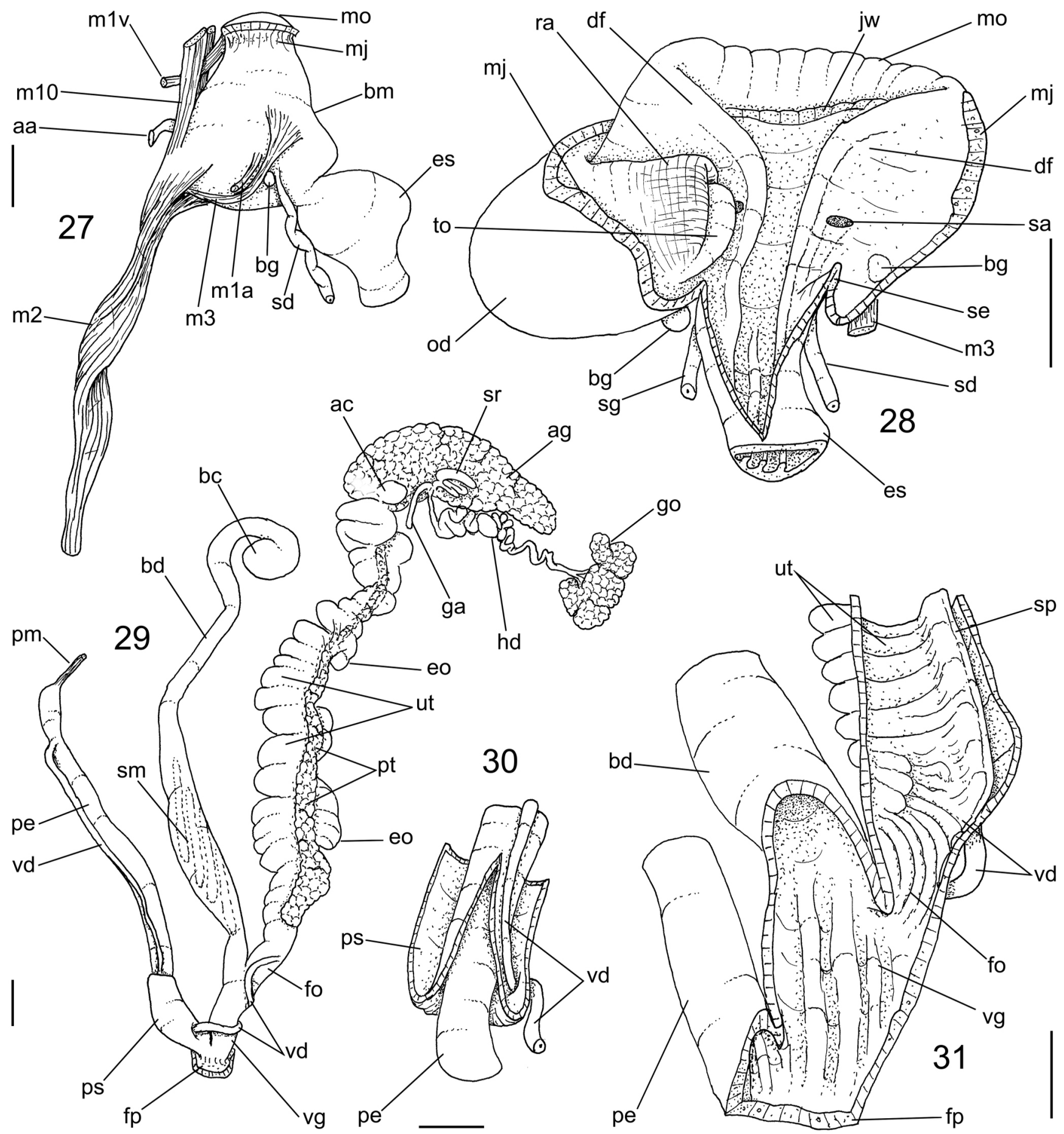

Figures 27-31. Drymaeus currais sp. nov. anatomy; (27) Foregut, left view. (28) Buccal mass, ventral view, odontophore (od) partially sectioned and deflected to left, right buccal ganglion (bg) and salivary duct (sd) (right in Fig.) insertion seen by translucency. (29) Genital system, dorsal view, partially uncoiled, some spermatophores (sm) seen by translucency. (30) Penis, detail of its proximal region, penis sheath (ps) partially sectioned. (31) Genital ducts, detail of its anterior region, some structures sectioned longitudinally. Scales $=2 \mathrm{~mm}$. 
moviduct length, $2 / 3$ its anterior width (Fig. 29: pe); penis muscle inserting terminally, very short (Fig. 29: pm). Epiphallus 1/8 penis' length, located as short terminal continuation of penis (Figs. 29, 34: eh), inner surface with narrow, irregular longitudinal folds, located close from each other, uniformly sized (Fig. 34: eh). Vas deferens inserted subterminally in penis tip (Figs. 29, 34: vd). Internal penial surface lacking clear sub-chambers (Fig. 34: pe); short smooth middle region posterior region with 5-6 longitudinal, narrow, low folds; anterior region with pair of larger folds (Fig. 34). Penis shield occupying basal 1/4 of penis length (Figs. 29, 30: ps); vas deferens piercing its walls close to its base (Fig. 30). Genital pore round, simple.

Central nervous system: (Figs. 35, 36) cerebral ganglia located dorsally in middle level of buccal mass, pedal ganglia located more posteriorly. Pair of cerebral ganglia (ce) widely fused with each other; cerebral commissure invisible; each ganglion about as wide as adjacent esophageal section (Fig. 25: nr); several wide nerves originating in cerebral antero-lateral region. No clear cerebral node or gland. Two pairs of parallel connectives between cerebral ganglia and pedal ganglia. Pair of pedal ganglia (pp)

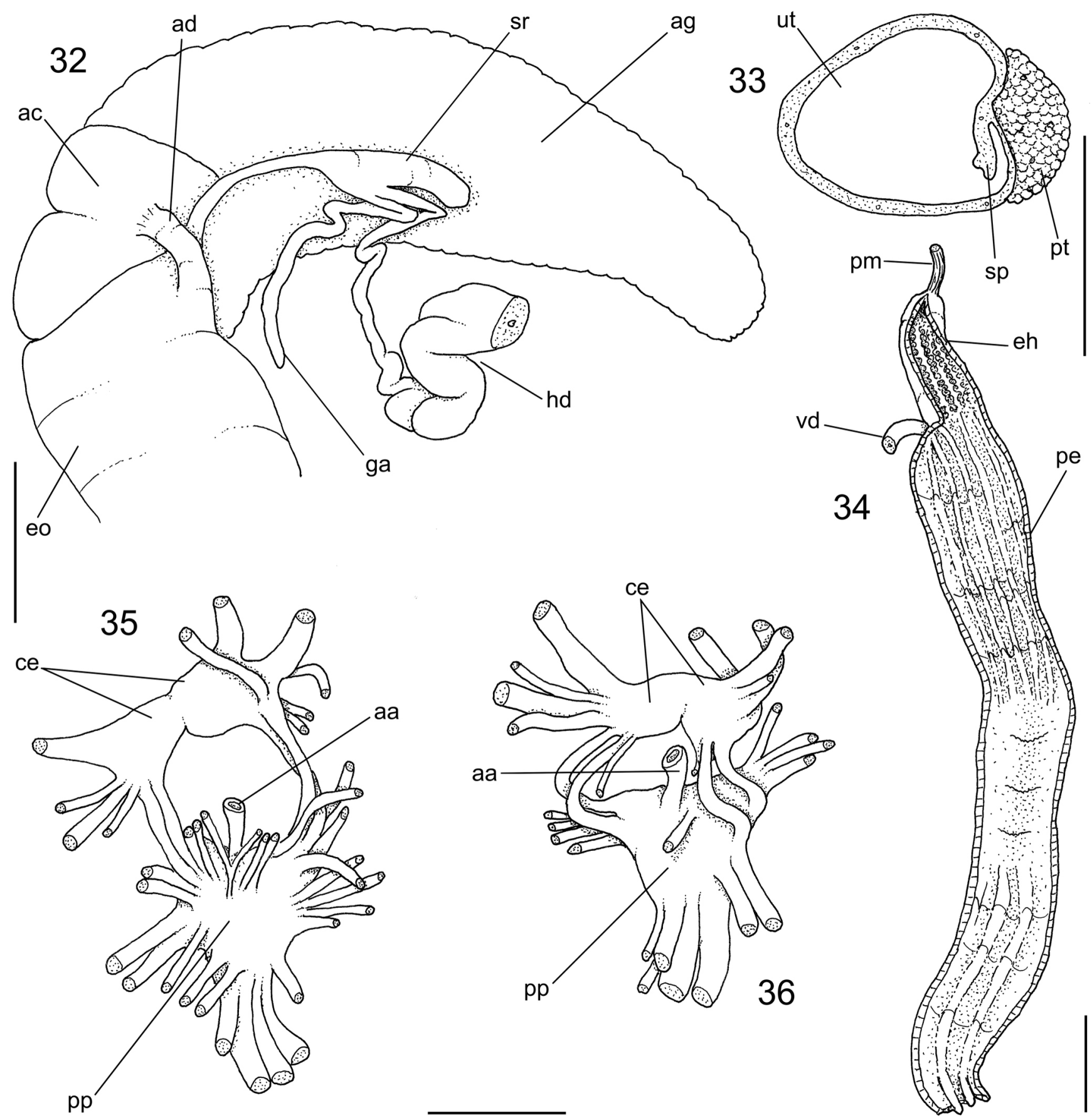

Figures 32-36. Drymaeus currais sp. nov. anatomy; (32) Middle region of genital system, ventral view, some structures seen if albumen gland (ag) was transparent. (33) Spermoviduct, transverse section in its middle level. (34) Penis, ventral view, opened longitudinally. (35) Nerve ring, dorsal view. (36) Same, ventral view. Scales $=2 \mathrm{~mm}$. 
forming single mass located opposite to cerebral ganglia, slightly larger sized than cerebral ganglia. No differentiable individual pedal ganglion detectable.

Distribution: Endemic from Guapirá Island, Currais Archipelago (Fig. 1).

Habitat: The animals were found in a shaded area, inhabiting both the trunks and the abaxial part of the leaves of the tree vegetation of the Ombrophiles Dense Forest that covers the island. They were also located in the bromeliads of the rocky shores that are part of the pioneer rupicolous vegetation.

Measurements: (length and width in $\mathrm{mm}$ ) Holotype MZSP 150548 (Figs. 2-4): 29.6 by 10.6; paratypes MZSP 135683: \#1 (Figs. 5-6), 30.7 by 14.5; \#2 (Figs. 7-8), 25.2 by 12.7.

\section{DISCUSSION}

The closest species from Drymaeus currais sp. nov., undoubtedly, are the also insular species $D$. castilhensis and D. micropyrus Simone \& Amaral, 2018. As informed in the 'Introduction', the shell of $D$. currais sp. nov. is practically indistinguishable from that of $D$. castilhensis, in a first tentative identification. In this aspect, the same taxonomical comparisons of both Simone \& Amaral's (2018) species to other congeneric species can be herein applied. The present discussion is, thus, focused on the distinction amongst these three species.

The distance between the Castilho Island, location of occurrence of $D$. castilhensis, and the Currais Archipelago, location of occurrence of $D$. currais sp. nov., is of about $70 \mathrm{~km}$ of sheer ocean. This distance certainly precludes any kind of gene flow. A possible transportation via oceanic birds sounds implausible, as the snails are quite large, and would hardly resist a $70 \mathrm{~km}$ flight of a bird. Much closer is the mainland coast ( $5 \mathrm{~km}$ for Currais, $\sim 7 \mathrm{~km}$ for Castilho), and it is possible to theorize that a continental population can genetically connect both insular populations. However, such kind of Drymaeus is unknown in the continental coastal stretch between São Paulo and Paraná. Queimada Pequena island, location of occurrence of $D$. micropyrus, is further $30 \mathrm{~km}$ norther.

The description above includes also the effort in distinguishing $D$. currais sp. nov. from $D$. castilhensis, as it is mostly comparative, mainly in the anatomical part. Thus, a complete distinction between the two species are better explained along the description. In the present discussion, the more important distinctions are reported, as follows. The shell protoconch of $D$. currais sp. nov. (Fig. 9) is slightly taller and more acuminated than those of $D$. castilhensis and D. micropyrus (Simone \& Amaral, 2018 , figs. 8, 10); additionally, the protoconch of $D$. currais sp. nov. is $\sim 60 \%$ smaller than that of $D$. micropyrus. In average, the ventral region of the last whorl of $D$. currais sp. nov., mainly in the region above peristome, is slightly broader than those of the other two species; this is a pa- rameter difficult to measure, but the peristome of $D$. currais sp. nov. is approximately as wide as the distance between the superior implantation of outer lip and the right edge of the last whorl profile (Figs. 2, 5, 7), while in the other two species, this parameter is $\sim 80 \%$. The shell color patterns of $D$. currais sp. nov. are really indistinguishable from $D$. castilhensis, however it presents the same differences of $D$. micropyrus than those reported for $D$. castilhensis in the original description.

Anatomically, Drymaeus currais sp. nov. differs from $D$. castilhensis mainly by: more elongated aperture of the ureter, $\sim 1 / 3$ of the ureter length (Figs. 24, 26), against $\sim 1 / 3$ of $D$. castilhensis; much more richness of pulmonary vessels, mainly in right side of the pulmonary vein (Fig. 24), these vessels are much less developed in D. castilhensis; salivary glands more anteriorized located, with the respective ducts much shorter (Fig. 25: sg, sd); single duct to anterior lobe of the digestive gland (Fig. 25: dd), which is bifid, each branch connecting in different sides of the adjacent intestinal loop in D. castilhensis; intestinal loops much shorter at visceral mass (Fig. 25: in); jaw plate with less developed medial narrowing (Fig. 10: jw); odontophore with pairs $\mathrm{m} 1 \mathrm{a}$ and $\mathrm{m} 3$, both absent in $D$. castilhensis; genital carrefour area with genital appendix (Fig. 32: ga); duct of the albumen gland single (Fig. 32: ad), while it is double in D. castilhensis; epiphallus internal folds more uniform sized, while $D$. castilhensis has a strong large longitudinal fold; separation of the vas deferens much more posterior (Fig. 31: vd), while that of $D$. castilhensis is much more anteriorized (Simone \& Amaral, 2018: fig. 50). This is a considerable anatomical amount of differences for so close related species. From $D$. micropyrus, $D$. currais sp. nov. differs in the same characters as those reported by Simone \& Amaral (2018) for $D$. castilhensis, mainly in the separation of the duct of the albumen gland and insertion of seminal receptacle (Fig. 32), and by tall longitudinal fold separating masculine from feminine regions of the spermoviduct (Fig. 33: sp).

As the taxonomy of the bulimulids, Drymaeus in particular, is practically only based on shell characters, several cryptic species may exist in the genus. The present study is an example, as two populations with almost indistinguishable shells hide higher anatomical differences, which can be interpreted as different species. The extra-shell characters, thus, must be explored as much as possible in these organisms.

\section{ACKNOWLEDGEMENTS}

The authors would like to thank both referees for important suggestions; to Antonio Ostrensky and GIA - Integrated Aquaculture and Environmental Studies Group at the Federal University of Paraná for the logistical and financial support for the project; ICMBio - Chico Mendes Institute for Biodiversity Conservation for granting environmental licenses; Fabio Moreira Correa, environmental analyst at ICMBio for support at all times; Carlos João Birckolz for drawing up the archipelago map 
and Lara Guimarães for the SEM exam that was performed at the MZSP Laboratory of Electronic Microscopy. The collect was performed under license SISBIO 47215-3.

\section{REFERENCES}

Bigarella, J.J.; Mousinho, M.R. \& Silva, J.X. 1965. Pediplanos, pedimentos e seus depósitos correlativos no Brasil. Boletim Paranaense de Geografia, (16-17): 117-151.

Birckolz, C.J.; Salvador, R.B.; Cavallari, D.C. \& Simone, L.R.S. 2016. Illustrated checklist of newly described (2006-2016) land and freshwater Gastropoda from Brazil. Archiv für Molluskenkunde, 145(2): 133-150.

Borzone, C.A.; Gutseit, K.C. \& Soares, C.R. 1999. Sedimentos e macrofauna bentônica da zona de águas rasas da praia de Matinhos, Paraná, Brasil. Atlântica, 21: 43-58.
Instituto Chico Mendes de Conservação da Biodiversidade (ICMBio). 2020. PARNA Marinho das Ilhas dos Currais. Available: https://www.icmbio. gov.br/portal/unidadesdeconservacao/biomas-brasileiros/marinho/ unidades-de-conservacao-marinho/4126-parna-marinho-das-ilhasdos-currais. Access: 02/04/2020.

Roderjan, C.V.; Galvão, F.; Kuniyoshi, Y. \& Hatschbach, G. 2002. As unidades fitogeográficas do Estado do Paraná, Brasil. Ciência \& Ambiente, 24: 78-118.

Simone, L.R.L. 2006. Land and freshwater Molluscs of Brazil. São Paulo, EGB/ FAPESP.

Simone, L.R.L. \& Amaral, V.S. 2018. Insular life: new endemic species from São Paulo oceanic islands, Brazil (Pulmonata, Bulimulidae), as example of endemicity. Journal of Conchology, 43(2): 167-187.

Vanhoni, F. \& Mendonça, F. 2008. 0 Clima do litoral do Estado do Paraná. Revista Brasileira de Climatologia, 3: 49-63. 